\title{
Growth hormone and the heart in growth hormone deficiency-what have we learned so far?
}

\author{
Jörgen Isgaard ${ }^{1}$ Antonio Cittadini ${ }^{2}$
}

Received: 22 November 2016 / Accepted: 8 December 2016 / Published online: 16 December 2016

(C) Springer Science+Business Media New York 2016

Recombinant human growth hormone $(\mathrm{GH})$ has been available now for almost 30 years to use as replacement therapy in children and adults suffering from GH deficiency (GHD). One of the early recognized targets for the beneficial effects of GH replacement therapy was the cardiovascular system. GHD affects the cardiovascular system on many levels. Lack of GH results in direct effects on the heart including decreased ventricular mass and cardiac output, reduced exercise capacity and impairment of both diastolic and systolic function (for review see [1]).

In addition to this direct impact of GHD on the heart, some studies suggest increased peripheral resistance (the resistance influenced by blood pressure and cardiac output which must be overcome to push blood through the circulatory system to create flow) due to low levels of GH although results are conflicting [1]. Possible mechanisms include decreased nitric oxide production [2] or decreased expression of vascular smooth muscle $\mathrm{K}_{\mathrm{ATP}}$ channel [3]. Moreover, a number of cardiovascular risk factors have been identified in patients lacking GH. Most established findings include insulin resistance [4, 5], unfavourable changes in serum lipid pattern with increased serum lowdensity lipoprotein-cholesterol concentration [6], decreased fibrinolysis [7], augmented sympathetic nervous activity [8], and negative effects on body composition. Replacement

Jörgen Isgaard

jorgen.isgaard@medic.gu.se

1 Department of Internal Medicine and Nutrition, Sahlgrenska Academy at the University of Gothenburg and Sahlgrenska University Hospital, Gothenburg, Sweden

2 Department of Translational Medical Science, Federico II University, Naples, Italy therapy with GH to GHD patients tends to correct most of these aberrations in cardiovascular function [9].

The new study by Boschetti has addressed if coronary flow reserve (CFR) is affected in GHD patients in fairly early stages of the disease [10]. This is novel and interesting since CFR is considered to be an early marker of impaired myocardial microcirculation that may be present before manifest atherosclerosis and stenosis. Data from Boschetti and collaborators show that CFR is significantly decreased in 14 GHD patients compared to matched controls. Moreover, 12 months of GH replacement therapy to GHD patients normalizes CFR and also improves diastolic function. A limitation of the study is obviously the small number of patients and the clinical significance of the findings since both CFR and E/A (the studied echocardiographical marker for diastolic function) were both within the lower normal range. Moreover, it is not clear from the present findings if the improvement in CFR is the result of direct effects of GH and/or IGF-I on the heart or secondary to improvement in blood lipid status. However, if CFR can be confirmed to be decreased in other studies, it can potentially be an important early marker for GHD patients who are at increased risk to develop cardiovascular disease.

Compliance with ethical standards

Conflict of interest The authors declare that they have no competing interests.

\section{References}

1. J. Isgaard, M. Arcopinto, K. Karason, A. Cittadini, GH and the cardiovascular system - an update on a topic at heart. Endocrine 48(1), 25-35 (2015) 
2. R. Böger, C. Skamira, S. Bode-Böger, G. Brabant, A. von zur Mühlen, J. Frölich, Nitric oxide may mediate the hemodynamic effects of recombinant growth hormone in patients with acquired growth hormone deficiency. J. Clin. Invest. 98, 2706-2713 (1996)

3. A. Tivesten, A. Barlind, K. Caidahl, N. Klintland, A. Cittadini, C. Ohlsson, J. Isgaard, Growth hormone-induced decreased blood pressure is associated with increased mRNA levels of the vascular smooth muscle KATP. J. Endocrinol. 183, 195-202 (2004)

4. J.-O. Johansson, J. Fowelin, K. Landin, I. Lager, B.-Å. Bengtsson, Growth hormone-deficient adults are insulin-resistant. Metabolism 44, 1126-1129 (1995)

5. F. Hew, M. Koschmann, M. Christopher, C. Rantzau, A. Vaag, G. Ward, H. Beck-Nielsen, F. Alford, Insulin resistance in growth hormone-deficient adults: defects in glucose utilization and glycogen synthase activity. J. Clin. Endocrinol. Metab. 81, 555-564 (1996)

6. W. Drake, S. Howell, J. Monson, S. Shalet, Optimizing GH therapy in adults and children. Endocr. Rev. 22, 425-450 (2001)
7. J.-O. Johansson, K. Landin, L. Tengborn, T. Rosén, B.-Å. Bengtsson, High fibrinogen and plasminogen activator inhibitor activity in growth hormone-deficient adults. Arterioscler. Thromb. 14, 434-437 (1994)

8. Y. Sverrisdóttir, M. Elam, B.-Å. Bengtsson, G. Johannsson, Intense sympathetic nerve activity in adults with hypopituitarism and untreated growth hormone deficiency. J. Clin. Endocrinol. Metab. 83, 1881-1885 (1998)

9. C. Gazzaruso, M. Gola, I. Karamouzis, R. Giubbini, A. Giustina, Cardiovascular risk in adult patients with growth hormone $(\mathrm{GH})$ deficiency and following substitution with GH-an update. J. Clin. Endocrinol. Metab. 99(1), 18-29 (2014)

10. M. Boschetti, S. Agosti, V. Albanese, L. Casalino, C. Teti, G. P. Bezante, C. Brunelli, M. Albertelli, D. Ferone, One year GH replacement therapy reduces early cardiac TOD (Target Organ Damage) in adult GHD patients. Endocrine (2016). doi:10.1007/ s12020-016-0951-4 